\title{
A IMPORTÂNCIA CULTURAL DA ARTE NA VISÃO DE SUSANNE LANGER
}

\author{
THE CULTURAL IMPORTANCE OF ART IN THE VIEW OF SUSANNE LANGER \\ Nathália Cristina Medeiros Maia. ${ }^{1}$
}

\section{http://dx.doi.org/10.52641/cadcaj.v6i4.547}

RESUMO: Este artigo tem como objetivo apresentar a perspectiva de Susanne K. Langer sobre a importância cultural da arte, a partir da obra Ensaios Filosóficos, mais especificamente, a partir da conferência pronunciada na Universidade de Siracusa em 1958. Este trabalho tem como foco principal a identificação das formas simbólicas da arte, para que possamos distingui-las do simbolismo discursivo, assim como tem o propósito de investigar os tipos de expressão humana conforme a teoria estética de Langer, com base em algumas das suas influências mais importantes, tais como: Alfred North Whitehead e Ernst Cassirer.

Palavras-chave: Formas simbólicas da arte; Simbolismo discursivo; Expressão humana; Estética.

ABSTRACT: The objective of this article is present the perspective of Susanne K. Langer about the cultural importance of the art in Philosophical Sketches, more specifically, from the conference pronounced at 1958 in the University of Syracuse. This work have as principal focus, the identification of symbolic forms of the art, so that we can distinguish of the discursive symbolism, as well have also the purpose of investigate the types of human expression course the Langer's aesthetic theory and her greatest influences: like Alfred North Whitehead e Ernst Cassirer.

Keywords: Symbolics forms of the art; Discursive symbolism; Expression human, Aesthetic.

\section{INTRODUÇÃO}

A obra Ensaios Filosóficos da filósofa norte-americana Susanne K. Langer (1895 - 1985), reúne vários ensaios e conferências sobre diversas áreas do conhecimento, tais como: Psicologia, Linguística, Estética, Sociologia, Biologia e entre outras ciências. No entanto, este presente artigo tem como objetivo geral elaborar uma análise descritiva, ao usar como base o quinto capítulo do texto escolhido, intitulado A Importância Cultural da Arte, no qual diz respeito ao pronunciamento de Langer durante a conferência que ocorreu na Universidade de Siracusa no ano de 1958, onde

\footnotetext{
${ }^{1}$ Graduanda em Filosofia pela UFRN. Bolsista no Programa de Educação Tutorial (PET).
} 
começou a especular sobre o desenvolvimento artístico e cultural, desde as mais antigas tradições, até a chegada da contemporaneidade.

Dentre os objetivos específicos deste artigo, podemos citar os seguintes: analisar a visão estética de Susanne Langer; refletir sobre alguns dos conceitos centrais acerca da concepção artística da autora, como por exemplo sobre a auto-expressão e a expressão em si; distinguir o simbolismo discursivo das formas simbólicas da arte; descrever detalhadamente sobre a importância da arte no contexto da cultura e do desenvolvimento humano; relacionar o pensamento da filósofa com algumas das suas maiores referências, isto é, Alfred North Whitehead (1861 - 1947) e Ernst Cassirer (1874 - 1945); elaborar uma hipótese sobre a importância das maneiras de sentir a partir da educação dos sentimentos e das emoções, no contexto da arte e da cultura.

A justificativa para a execução deste trabalho está vinculada ao fato de que Langer ainda é uma filósofa pouco estudada no Brasil. Embora tenha influenciado a corrente artística do neoconcretismo, que se fundou no país em meados dos anos 1950, Susanne Langer continua sendo pouco estudada no contexto acadêmico. Além disso, por se tratar de uma das primeiras mulheres a se formarem em Filosofia nos Estados Unidos, e também por se tratar da primeira filósofa da América do Norte a ficar reconhecida por sua importante contribuição acadêmica, torna este estudo ainda mais necessário para uma reflexão filosófica inclusiva e original. Em suma, este texto dividido em três partes - Introdução, Desenvolvimento e Conclusão - visa investigar minuciosamente a importância artística na conjuntura histórica, social, ética, estética e principalmente, cultural, a fim de apresentar a relevância da arte em relação ao desenvolvimento da humanidade.

\section{A EDUCAÇÃO DOS SENTIMENTOS ATRAVÉS DA ATIVIDADE ESTÉTICA}

No ponto de vista langeriano, toda cultura permite a evolução de algum tipo de arte, assim como permite a evolução da linguagem. Embora algumas tradições anteriores, não estejam marcadas por nenhum traço místico ou mágico-religioso, as antigas heranças culturais ficaram marcadas e reconhecidas pelas suas variadas formas de expressividade artística. Sobre isso, diz Langer: 
Toda cultura desenvolve alguma espécie de arte tão certamente quanto desenvolve a linguagem. Algumas culturas primitivas não possuem nenhuma mitologia nem religião reais, mas todas possuem alguma arte - a dança, o canto, o desenho (algumas vezes só em utensílios ou no corpo humano). A dança, sobretudo, parece ser a mais antiga arte aperfeiçoada (LANGER, 1971, p. 81).

Nesse sentido, a filósofa pensa que a diversidade cultural está intrinsecamente associada ao aprimoramento das formas de expressividade humana, tanto em termos artísticos, quanto em termos linguísticos. A arte se reinventa frequentemente por meio da criatividade provinda do imaginário, seja através da dança, do canto, do desenho, da pintura, ou das outras variadas formas de expressão artística decorrentes das tradições, até a chegada da era contemporânea.

$\mathrm{Na}$ cosmovisão de Langer, a arte pode ser melhor compreendida conforme a ideia adotada pela maior parte dos artistas, ou seja, a partir da defesa do processo artístico como sendo a síntese dos conjuntos de hábitos humanos, tais quais, os seus respectivos sentimentos e emoções, que são sinalizados a partir de uma conexão interior. Além disso, Susanne considera a arte como necessária para apurar riquezas de valor cultural nas sociedades. Caso contrário, se não houver arte, em um contexto de vigência econômica e militar, a condição social será pobre ao comparar-se com as marcas artístico-culturais dos grupos sociais originários. Nesse sentido, Langer escreve: "A Arte é, na verdade, a ponta de lança do desenvolvimento humano, social e individual. A sua vulgarização constitui o sintoma mais certo de declínio ético" (LANGER, 1971, p. 81-82). Todas as formas de criação artística contribuem com o progresso das relações humanas, com o aprimoramento das maneiras de sentir, com uma educação transformadora das capacidades mentais que estão marcadas por atributos sensitivos, intuitivos e imaginários. Por essa razão, durante o decorrer das gerações, a humanidade vai ao encontro de novos modos de lidar com o mundo, na medida em que descobre novas formas de sentir e de apreender o sentido da vida. Diante dessa perspectiva, é possível citar o seguinte fragmento:

A arte ajusta-se melhor à convicção da maioria dos artistas segundo a qual ela é o epítome da vida humana, o registro mais fiel dos vislumbres interiores e dos sentimentos, e de que a sociedade mais vigorosamente militar ou econômica, sem arte, é pobre em comparação com a tribo mais primitiva e selvagem de pintores, dançarinos ou entalhadores de ídolos (LANGER, 1971, p. 81).

$\mathrm{Na}$ concepção da autora, a arte é essencial para o avanço da humanidade, tanto no sentido particular, do indivíduo, quanto no sentido universalizado, das relações interpessoais. A banalização 
da importância artística contraria os valores e os hábitos sociais e culturais, os quais, na realidade, são considerados por ela como fundamentais para o desenvolvimento humano. Segundo o pesquisador Vincent Colapietro, Susanne Langer precisou recorrer ao estudo minucioso acerca do aspecto criativo da arte em relação às demais culturas, através de uma cuidadosa investigação sobre os demais tipos de ofícios humanos que envolvem o fazer artístico. Sobre essa análise, escreve Colapietro: "A questão da criatividade na arte e, de modo mais geral, em todos os campos do esforço humano foi central para as explorações semióticas de Susanne Langer" (COLAPIETRO, 1997, p. 01, tradução autoral). ${ }^{2}$. Assim, a arte é considerada por Langer como indispensável para a sustentação dos costumes das sociedades, assim como direciona a humanidade ao seu mais pleno avanço social e cultural, enquanto que a desvalorização dos processos artísticos conduz as sociedades em direção à decadência dos valores éticos.

No primeiro momento de seu ensaio sobre A Importância Cultural da Arte, Susanne define a arte como uma espécie de prática criativa, a qual origina formas vinculadas às percepções expressivas dos sentimentos, e, das emoções humanas. Na perspectiva de Langer, as expressividades artísticas são marcadas por influências subjetivas, e é através delas que a criação da obra de arte pode realizar-se objetivamente. Conforme evidencia-se na seguinte passagem:

A arte no sentido aqui proposto - ou seja, o termo genérico abrangendo pintura, escultura, arquitetura, música, dança, literatura, drama e cinema pode ser definida como a prática de criar formas perceptíveis expressivas do sentimento humano (LANGER, 1971, p. 82).

No segundo momento de sua conferência, ela parece levantar um paradoxo, afirmando que a arte não é prática. Nas palavras de Langer: "Mas a Arte não é prática; não é Filosofia nem Ciência; não é religião, nem moralidade, nem mesmo crítica social (como muitos críticos dramáticos supõem que a comédia seja)" (LANGER, 1971, p. 88). As idealizações formadas através das projeções mentais concebidas pelo imaginário, são vistas por Susanne como primordiais para que as obras de arte possam se realizar. Por sua vez, a imaginação do artista origina a expressividade criativa das suas produções, que representam os seus traços subjetivos, formados pela sua fonte primitiva.

No pensamento de Susanne, as criações artísticas têm de integrar formas, as quais, devem parecer familiares à perceptividade humana. Assim, a perspectiva langeriana, propõe algumas possibilidades acerca dos tipos de formas perceptuais existentes, que podem ser caracterizadas da

\footnotetext{
2 "The question of creativity in art and, more generally, in all fields of human endeaver was central to Susanne Langer's semiotic explorations" (COLAPIETRO, 1997, p. 01).
} 
seguinte maneira: através da identificação de formas fixas, como por exemplo, as dos objetos concretos; formas mutáveis, como por exemplo, as dos cânticos, dos hinos, e dos movimentos artísticos corporais; ou formas aparentes às nossas percepções, indicadas pelas impressões imaginárias, como por exemplo, sugerem as poesias, os romances, e as artes literárias em geral. Tal como revela-se neste fragmento:

É neste sentido de aparecimento à nossa percepção que uma obra de arte constitui uma forma. Pode ser uma forma permanente como a de um edifício ou de um vaso ou de um quadro, ou uma forma transiente, dinâmica, como a de uma melodia ou de uma dança, ou ainda uma forma sugerida à imaginação, como a passagem de eventos puramente imaginários, aparentes, que constitui uma obra literária (LANGER, 1971, p. 84).

As formas das obras de arte nos são comunicadas quando elas se tornam perceptíveis aos nossos sentidos. Langer considera as criações artísticas como sendo engendradas pela força primitiva do imaginário, conforme afirma na seguinte passagem: "É esta primitiva força humana - a imaginação - que engendra as artes e é, por seu turno, diretamente afetada por suas produções” (LANGER, 1971, p. 88). Podemos dizer que as produções artísticas podem ser formadas de modo concreto, transitório, e, inclusive, de modo imaginativo, pois esse último é considerado por Langer como a fonte primitiva que atribui força às criações expressivas que se relacionam com a sensibilidade existente no nosso mundo interior.

$\mathrm{Na}$ visão de Susanne, existem dois significados fundamentais para o termo "expressão". O primeiro significado diz respeito as formas de auto-expressão, ou seja, relaciona-se com a nossa realidade interior, de caráter subjetivo, emocional, sentimental, sensitivo, e, portanto, de caráter sintomático. Podemos citar como exemplo algumas possibilidades de manifestações autoexpressivas: a tristeza, a alegria, a raiva, a angústia, o medo, assim como qualquer experiência introspectiva que diga respeito ao indivíduo isoladamente. O segundo significado diz respeito à expressividade discursiva, de caráter abstrato, lógico, conceitual e simbólico, como por exemplo: a linguagem, a matemática e todo pensamento racional associado à realidade objetiva. Nas palavras de Langer:

A palavra 'expressão' possui dois significados principais. Num sentido significa auto-expressão - dar vazão a nossos sentimentos. Nesse sentido, relaciona-se a um sintoma do que sentimos[...] Em outro sentido, porém 'expressão' significa a apresentação de uma ideia, usualmente pelo emprego próprio e adequado de palavras. Mas o artifício pelo qual se apresenta uma 
ideia constitui o que chamamos símbolo, não sintoma (LANGER, 1971, p. 84).

Conforme Susanne, os nossos sentidos particulares se relacionam com as maneiras de autoexpressão, as quais condizem com os sintomas sensitivos mais íntimos de cada ser humano. Langer admite que os mecanismos discursivos da linguagem, não são capazes de conceber plenamente os sentimentos e as emoções decorrentes da auto-expressividade.

Ademais, a sensibilidade revela de modo perceptível, as experiências individuais que dizem respeito à consciência subjetiva, em termos sentimentais e emocionais. Enquanto que as expressões propriamente ditas consistem em afirmar objetivamente as manifestações do pensamento, por intermédio dos recursos simbólicos da linguagem discursiva. Para a filósofa, a emotividade e a sentimentalidade não são irracionais, como pensam muitos teóricos racionalistas, pois na verdade, a real natureza das percepções sensórias está muito além das delimitações conceituais, do simbolismo lógico-discursivo.

A razão por que a linguagem se mostra aqui tão impotente não é, como tanta gente supõe, o fato de o sentimento e a emoção serem irracionais; ao contrário, parecem irracionais porque a linguagem não ajuda a fazê-los concebíveis, e a maioria das pessoas não pode conceber coisa alguma sem o andaime lógico das palavras [...] A natureza real do sentimento é algo que a linguagem como tal - como simbolismo discursivo - não pode exprimir (LANGER, 1971, p. 86).

Susanne Langer concorda que a auto-expressão não deve ser considerada inválida à luz da razão, uma vez que os atributos sentimentais e emocionais ultrapassam os limites objetivos da linguagem. Por esse motivo, a abstração racional não é capaz de compreender conceitualmente os sintomas das experiências advindas da realidade interior, e nem mesmo é capaz de observar objetivamente o simbolismo artístico enquanto formulação de novos sentimentos e emoções, pois, as vivências interiores não podem ser plenamente descritas, e nem delimitadas por estruturas concernentes à realidade exterior. Em outras palavras, a realidade subjetiva é incomensurável em relação aos critérios estabelecidos pela normatividade linguística. Robert E. Innis concorda com essa perspectiva, através da seguinte passagem:

A teoria estética de Langer, bem como a sua teoria do mito, da religião, e do ritual, verá então a chave para o entendimento da arte na noção expandida de uma sintaxe não-discursiva que não denota muito os fatos como exemplifica 
ou expressa as "formas de sentimento" e as formas de significado que não podem ser objetivadas em termos discursivos, transcendendo, como o fazem, as "expressões" (INNIS, 2009, p. 18, tradução autoral). ${ }^{3}$

A teoria estética de Susanne, defende que as expressões artísticas são similares à criação de formas simbólicas. Na visão dela, a arte é expressiva, quando novas formas de sentir são elaboradas. Langer defende a ideia de que o simbolismo artístico está além das dimensões conceituais, e, por essa razão, não pode ser representado de maneira plena pelo discurso, pois a realidade interior de cada sujeito envolve uma vasta quantidade de emoções e sentimentos, os quais são inconcebíveis às rigorosas determinações do viés lógico-discursivo.

Alfred North Whitehead foi uma importante influência para a construção do pensamento de Susanne Langer, principalmente sobre o que diz respeito aos seus estudos referentes à filosofia da mente, visto que ele foi o seu professor em Radcliffe. Assim como Langer, Whitehead concebeu uma visão admiradora acerca do potencial criativo das artes, e também, classificou as manifestações artísticas como originais, tanto no aspecto físico, quanto no aspecto puramente imaginativo. $\mathrm{O}$ fundador da filosofia do processo. ${ }^{4}$, considerado por Susanne como seu grande mestre e amigo, pensou a arte como possuidora de um atributo curativo nas vivências humanas, quando ela transparece as visões íntimas que dizem respeito à verdade totalizante, na qual concerne a essência natural das coisas existentes, como podemos observar na seguinte passagem de sua obra Adventures of Ideas: "A arte tem uma função curativa na experiência humana quando revela como que em um flash íntimo, a verdade absoluta referente a Natureza das Coisas" (WHITEHEAD, 1967, p. 272, tradução autoral) ${ }^{5}$. Enquanto Langer entende que a função original da arte consiste em tornar a realidade subjetiva uma realidade objetiva, Whitehead entende que a arte possui uma função salutar, pois ela é capaz de promover a cura através das suas revelações interiores, acerca da verdade totalizante que diz respeito aos fenômenos naturais da vida.

As manifestações artísticas produzem expressões que são captadas por meio das percepções sensoriais, emocionais e sentimentais. Podemos citar como exemplo a experiência musical: quando algum músico utiliza de um determinado instrumento, para que ele possa expressar

\footnotetext{
3 "Langer's aesthetic theory, as well as her theory of myth, religion, and ritual, will then see the key to understanding art in the expanded notion of a non-discursive syntax that not so much "denotes" facts as exemplifies or expresses the 'forms of feeling' and forms of meaning that are not able to be objecrified in discursive terms, transcending, as they do, the 'sayable'"' (INNIS, 2009, p. 18).

${ }^{4}$ A filosofia do processo, fundada por Alfred North Whitehead $(1861-1947)$, trata de especular sobre a realidade metafísica, diante de um contexto transiente e dinâmico, de constantes mudanças físicas.

5 "Art has a curative function in human experience when it reveals as in a flash intimate, absolute Truth regarding the Nature of Things" (WHITEHEAD, 1967, p. 272).
} 
as suas maneiras de sentir, não só é necessário que ele se relacione com os efeitos sonoros produzidos pela música, mas também, e principalmente, é preciso que o instrumentalista tenha consciência da sua experiência interior, com o intuito de perceber os símbolos universais que são formados através das suas capacidades imaginárias e intuitivas, na medida em que torna as suas expressões perceptíveis à plateia, assim como educa e aperfeiçoa a concepção do artista durante a realização do processo criativo. $\mathrm{Na}$ linguagem de Langer:

A expressividade da Arte semelha a de um símbolo e não a de um sintoma emocional; é enquanto formulação de sentimento para a nossa concepção, que propriamente se diz de uma obra de arte que é expressiva (LANGER, 1971, p. 86-87).

Na visão de Adrienne Dengerink Chaplin, Susanne Langer considera que a arte e a música não são sintomas de auto-expressividade, mas na verdade são símbolos tal como considerava uma das maiores referências de Langer: o filósofo germânico Ernst Cassirer (1874 - 1945). Escreve Chaplin (2019, tradução autoral): "Para Langer, arte e música não são sintomas no sentido de autoexpressão ou catarse emocional, mas símbolos no sentido cassieriano de veículos para o significado". . Ainda que a auto-expressão humana tenha a função de dar vazão aos sintomas sentimentais e emocionais, a arte e a música não são sintomáticas, mas, simbólicas.

Diante desse prisma, a arte pode transformar a realidade subjetiva, em uma realidade objetiva, quando a manifestação artística pode ser captada pelos sentidos, através da criação das suas formas simbólicas, as quais expressam elementos da vida interior. Nesse sentido, Ernst Cassirer foi uma grande influência para Susanne Langer, uma vez que ele estudou sobre a importância das formas simbólicas no contexto da arte e da cultura.

Quando estamos absortos na intuição de uma grande obra de arte, não sentimos uma separação entre o subjetivo e o objetivo. Não vivemos a nossa realidade simples e corriqueira das coisas físicas, nem vivemos integralmente em uma esfera individual. Além dessas duas esferas detectamos um novo domínio, o domínio das formas plásticas, musicais, poéticas e estas têm uma universalidade real (CASSIRER, 1994, 238).

A seguinte passagem extraída do artigo O estatuto da música tonal em Susanne Langer, escrito por Azevedo Júnior e Viana do Amaral, pode servir como uma possível síntese da aproximação que existe entre as ideias de Langer e Cassirer: "As formas universais do sentimento, conteúdo

\footnotetext{
${ }^{6 " F o r ~ L a n g e r, ~ a r t ~ a n d ~ m u s i c ~ a r e ~ n o t ~ s y m p t o m s ~ i n ~ t h e ~ s e n s e ~ o f ~ s e l f-e x p r e s s i o n ~ o r ~ e m o t i o n a l ~ c a t h a r s i s, ~ b u t ~}$ symbols in the Cassierean sense of vehicles for meaning" (CHAPLIN, 2019).
} 
significativo da música, se articulam no tempo musical e se apresentam basicamente à audição" (AZEVEDO-JÚNIOR/AMARAL, 2020, p. 5). Na visão de Cassirer, as criações simbólicas de uma notável obra de arte, fazem com que o apreciador da criação artística, não sinta a divisão entre a realidade interior e a realidade exterior, pois ambas as realidades passam a se corresponder através das ligações da auto-expressão com a expressão, e colaboram conjuntamente para o surgimento de novas formas de sentir, como também, formulam novas maneiras de expressar os seus elementos sensitivos e intuitivos, por meio dos campos artísticos que integram os seus significados universais.

Langer examina a função mais importante da arte, e diz que ela cumpre o papel de tornar os sentimentos - de origem subjetiva - perceptíveis à realidade objetiva, para que possamos observá-los e melhor compreendê-los. Nessa perspectiva, a consciência relacionada à experiência interior, não está ao alcance dos símbolos lógicos e matemáticos, e nem mesmo das palavras e dos discursos já estabelecidos; pelo contrário, a realidade subjetiva é intangível e, portanto, não pode ser concebida pelas formas discursivas, as quais estão associadas à realidade objetiva.

\footnotetext{
A função primordial da Arte é objetivar o sentimento de modo que possamos contemplá-lo e entendê-lo. É a formulação da chamada 'experiência interior', da 'vida interior', que é impossível atingir pelo pensamento discursivo, dado que suas formas são incomensuráveis com as formas da linguagem e de todos os seus derivativos (por exemplo, a Matemática, a Lógica Simbólica) (LANGER, 1971, p. 87).
}

A arte atribui em si mesma o papel de dar forma às vivências relacionadas ao universo íntimo de cada sujeito, bem como formula as expressões que dizem respeito a essas vivências interiores. Assim, a prática da arte é capaz de manifestar objetivamente os aspectos sensíveis dos sentimentos e das emoções humanas, de modo a tornar possível uma contemplação acerca das experiências interiores do artista, a partir da produção realizada exteriormente, de forma perceptível e detalhada, a fim de proporcionar um melhor entendimento sobre a vida subjetiva.

Os processos criativos das produções artísticas originam novas possibilidades de expressão, as quais permitem o surgimento de novas gerações capazes de criar diferentes modos de sentir e de lidar com os sentidos. No pensamento de Langer, a imaginação é a forma simbólica mais primitiva da mente humana, anterior até mesmo à abstração conceitual, proveniente do pensamento racional. Ela considera que a imaginação é a causa da natureza dos sonhos, da fé religiosa, da racionalidade, da arte, da criatividade e das observações genéricas e verdadeiras. Conforme é exposto no seguinte fragmento: 
A imaginação é provavelmente o mais antigo traço mental tipicamente humano - mais antigo do que a razão discursiva; é provavelmente a fonte comum do sonho, da razão, da religião e de toda observação geral verdadeira. É esta primitiva força humana - a imaginação - que engendra as artes e é, por seu turno, diretamente afetada por suas produções (LANGER, 1971, p. 88).

No entanto, Susanne Langer afirma que o desenvolvimento da linguagem está correlacionado ao desenvolvimento da imaginação, conforme evidencia-se neste fragmento: "Linguagem e imaginação desenvolvem-se conjuntamente num regime de tutelagem recíproca" (LANGER, 1971, p. 89). A linguagem é importante para expandir a capacidade imaginária, assim como, a imaginação é importante para expandir e melhorar a expressividade conceitual, oriunda da linguagem.

Susanne considera que, enquanto a linguagem possui o papel de nos ajudar a construirmos expressões de modo consciente, em relação à realidade objetiva; as artes fazem com que tenhamos consciência da realidade interior, isto é, da experiência subjetiva. Assim, é possível conceber que as experiências objetivas podem se conectar com as experiências apresentadas pelas vivências subjetivas, das percepções sensoriais e vice-versa. Nessa perspectiva, a arte como manifestação da subjetividade, ao se aliar com os processos discursivos da linguagem, contribui diretamente com o aprimoramento ético dos hábitos e dos costumes coletivos.

O que o simbolismo discursivo - a linguagem no seu uso literal - nos faz no tocante à nossa consciência das coisas em derredor e à nossa própria relação com elas, as artes fazem em prol de nossa consciência da realidade subjetiva, do sentimento e da emoção; dão forma às experiências interiores e tornamnas, assim, concebíveis (LANGER, 1971, p. 89).

Após a leitura destas análises, surgem reflexões inquietantes que podem nos levar a refletir sobre algumas das questões fundamentais levantadas por Langer, como por exemplo: O período de florescimento das artes é capaz de conduzir as sociedades ao avanço cultural? Qual é o atributo principal para o surgimento de um período cultural? Essas são algumas questões possíveis a respeito do tema central tratado neste texto, isto é, sobre o que diz respeito à verdadeira importância da arte no contexto das tradições e dos costumes sociais e culturais. Langer responde a tais questões, através da seguinte passagem:

Essa influência que a Arte exerce sobre a vida dá-nos um indício da razão por que um período de florescimento das artes é capaz de conduzir a um avanço 
cultural: tal período formula uma nova maneira de sentir, e isso é o princípio de um período cultural (LANGER, 1971, p. 90).

O desenvolvimento das manifestações artísticas marcam o início de uma nova era cultural, e que, portanto, deve servir como base do aprimoramento social, para que a humanidade evolua conforme a formulação de significados correspondentes à sensibilidade humana, visto que a arte se relaciona intimamente com os pensamentos, os sentimentos e as emoções de cada pessoa. Escreve June Edwards sobre as expressões culturais presentes no pensamento de Langer: "Ela demonstrou não apenas a conveniência de utilizar as artes como uma atividade intelectual, mas também a necessidade de expressão artística em qualquer cultura" 7 . De maneira análoga a essa consideração de Edwards, podemos dizer que a linguagem de Susanne não é apenas discursiva, mas também artística, pois Langer mostra a relevância dos símbolos da arte em relação ao estudo dos símbolos lógico-filosóficos.

Na perspectiva de Susanne, as artes possuem a capacidade de objetivar as experiências de caráter subjetivo, assim como, fazem com que as nossas vivências exteriores e objetivas, sejam subjetivadas através da nossa conexão interior. Conforme Langer, para que exista uma educação dos sentimentos, é preciso que haja uma educação artística. As sociedades que não valorizam, e nem se importam, com as formas de expressão da arte, estão fadadas a uma má educação emocional.

As artes objetivam a realidade subjetiva, e subjetivam a experiência externa da Natureza. A educação artística é a educação do sentimento, e uma sociedade que a negligencia se entrega à emoção amorfa. Má arte é corrupção do sentimento. Este é um importante fator do irracionalismo que os ditadores e os demagogos exploram. (LANGER, 1971, p. 90).

Se má arte é corrupção do sentimento, então boa arte é purificação da sensibilidade. Aqueles que não apreciam o valor da arte, estão condenados à perda da educação e do desenvolvimento das formas expressivas dos seus sentimentos mais profundos acerca das suas realidades interiores. Os autoritários consideram a arte desnecessária para o avanço da humanidade, pois consideram-na como irracional e nada relevante para a supremacia dos seus cargos. Porém, a conduta autoritária demonstra ser impertinente a partir do momento em que visa exercer o domínio sobre as culturas, e quando constantemente revela o desprezo em relação ao potencial artístico que persiste em cada

\footnotetext{
7 "She demonstrated not only the desirability of using the arts as an intellectual activity, but also the need for artistic expression in any culture" (EDWARDS, 1984, p. 95).
}

Cadernos Cajuína, V. 6, N. 1, 2021, p. 351-363. 
pessoa que valoriza e busca entender os seus próprios sentimentos, a fim de aperfeiçoá-los por meio da arte. $\mathrm{Na}$ visão de Langer, os ditadores não são capazes de compreender as próprias experiências subjetivas, por causa da vulgarização que esses últimos fazem em relação às produções artísticas. No entanto, a filósofa pensa que a arte deve ser valorizada para a obtenção de um melhor reconhecimento a respeito da vida, visto que a contemplação da consciência interior corresponde a um patamar que está muito além de qualquer medida objetiva.

\section{CONCLUSÃO}

Por fim, na perspectiva de Susanne Langer, a arte possui um papel importante no desenvolvimento cultural, devido à capacidade de formular novas formas de contemplar os sentidos individuais e também sociais, visto que na visão da filósofa, as sociedades são marcadas por períodos que originam novas maneiras de sentir. Vale ressaltar que, a arte contribui diretamente com o aprimoramento ético dos hábitos e dos costumes coletivos. Diante do exposto, também foi possível analisar algumas ideias filosóficas que convergem com o pensamento langeriano, como por exemplo o pensamento de Whitehead a respeito da função primordial da arte, que segundo ele, possuiria uma ação curativa acerca da nossa realidade interior; de modo concomitante, Cassirer considera as manifestações artísticas como partes integrativas de um domínio simbólico universal. Ao levar em conta essas duas perspectivas, Langer passa a construir sua reflexão estética concernente às formas simbólicas da arte, assim como passa a estudar os tipos de expressão humana, relacionados às conjunturas da vida subjetiva e da vida objetiva. Assim, Susanne conclui que a imaginação criativa da arte, e a arte em si mesma, são fundamentais para que haja uma educação sentimental e emocional capaz de levar a sociedade como um todo em direção ao seu mais pleno avanço, sobre o qual conduz os indivíduos rumo ao despertar das suas consciências, até que possam atribuir novas criações de valor social e cultural.

\section{REFERÊNCIAS CITADAS:}


LANGER, Susanne Katherina. A importância cultural da arte, em Ensaios Filosóficos. Cultrix: São Paulo, 1981.

CASSIRER, Ernst. Ensaio sobre o homem: introdução a uma filosofia da cultura bumana. São Paulo: Martins Fontes, 1994.

AZEVEDO JÚNIOR, Ivânio Lopes de; AMARAL, Ilana Viana do. O estatuto da música tonal em Susanne Langer. Argumentos Revista de Filosofia, Fortaleza, ano 12, n. 23, p.42-52, jan/jun. 2020.

INNIS, Robert E. Susanne Langer in Focus: The Symbolic Mind. Bloomington e Indianapolis: Indiana University Press, 2009.

WHITEHEAD, Alfred North. Adventures of Ideas, The Free Press, New York, 1967.

COLAPIETRO, Vicent. 'Susanne Langer on Artistic Creativity and Creations'. In Semiotcs, edited by John Deely and C. W. New York: Peter Lang, 1997.

CHAPLIN, Adrienne Dengerink. 'The Philosophy of Susanne Langer: Embodied Meaning in Logic, Art and Feeling'. Bloomsbury, $1^{\text {st }}$ edition, 2019.

EDWARDS, June. "Susanne Langer: The Arts and Education.” Journal of Thought, vol. 19, no. 2, 1984, pp. $95-102$.

\section{REFERÊNCIAS CONSULTADAS:}

JÚNIOR, Ivânio Lopes Azevedo. A experiência musical e a interpretação simbólico-transcendental a partir de Ernst Cassirer e Susanne Langer. Griot : Revista de Filosofia, Amargosa - BA, v.19, n.3, p.230-246, outubro, 2019.

JEUNHOMME, Joseph. 'The Symbolic Philosophy of Susanne K. Langer'. Neue Zeitschrift Fur Systematische Theologie Und Religionphilosophie 27, no. 1 (1 January 1985): 159-76.

JULLIARD, Kell.; HEUVEL, Gary Van Den. 'Susanne K. Langer and the Foundations of Art Therapy'. Art Therapy 16, no. 3 (1999): $112-20$. 